http://dx.doi.org/10.18232/alhe.976

Artículos

\title{
Los costos de la modernización: cambios en los factores tierra y trabajo en Entre Ríos, Argentina, entre 1830 y 1880
}

\section{The cost of Modernization: changes in Land and Labor inputs in Entre Ríos, Argentina, between 1830 and 1880}

Julio Djenderedjian $1, *$ (D) 0000-0001-8812-2771

${ }^{1}$ Universidad de Buenos Aires, Buenos Aires, Argentina.

*Correspondencia: juliodjend@yahoo.com.ar

Resumen. Este trabajo intenta mostrar cómo afectó el encadenamiento de los costos de la tierra y del trabajo en el largo plazo a una economía rural dominada por la ganadería extensiva de exportación. Las rigideces desarrolladas durante años de bonanza, y las distorsiones generadas a partir del uso relativo de factores, introdujeron fragilidades particularmente evidentes en coyunturas críticas, y volvieron difícil el paso a pautas intensivas de explotación. Más aún, la misma crisis política y social pudo en parte al menos haber sido generada por esas rigideces. En todo caso, el análisis intenta mostrar que no puede atribuirse a explicaciones simplistas la conducta de los actores de entonces respecto de la inversión de capital y la innovación.

Palabras clave: salarios; tierra; producción agrícola.

Abstract. This article tries to show how the relationship between land and labor costs, in the long run, hit on a rural economy devoted to extensive cattle ranching and sheep breeding. Tensions developed in boom years, and distortions developed through relative use of factors, will be crudely exposed by a strong economic, political and social crisis, during which it was very difficult to find short-term solutions. Moreover,

CÓMO CITAR: Djenderedjian, J. (2019). Los costos de la modernización. Cambios en los factores tierra y trabajo en Entre Ríos, Argentina, entre 1830 y 1880. America Latina en la Historia Económica, 26(3), e976. DOI: 10.18232/alhe.976 
the crisis itself would have at least in part been generated by these tensions. Anyway, this research wants to show that it is not useful to find simple explanations to the actions of actors, regarding capital investment and innovation.

Key words: salaries; land; agricultural production.

JEL: N56.

Recibido: 22 de marzo de 2018.

Aceptado: 9 de agosto de 2018.

Publicado: 23 de mayo de 2019.

Organismo colaborador: Consejo Nacional de Investigaciones Científicas y Técnicas, Argentina.

\section{INTRODUCCIÓN}

El estudio de los ciclos económicos parece haber vuelto al centro de la escena del debate, en parte por episodios recientes de boom and burst (véase Gjerstad y Smith, 2014). Las distorsiones producidas por los cambios en los precios relativos de los factores, que pueden parecer poco importantes cuando hay bonanza, adquieren creciente dimensión en las coyunturas críticas. Esos cambios suelen condicionar fuertemente las decisiones de los actores, pero sólo en el mediano o largo plazos pueden apreciarse en plenitud sus consecuencias. Cuando, en un contexto de rápido crecimiento económico, las decisiones tomadas por el poder político más que corregir las distorsiones provocan por el contrario cambios de mayor magnitud en los precios relativos de los factores, y estos no son a su vez acompañados por transformaciones sustanciales en la ecuación de costos que compensen sus efectos, es evidente que se irán generando problemas que se manifestarán en plenitud a la llegada de la crisis.

En las páginas que siguen analizaremos la evolución del valor del trabajo y los otros factores de producción, y su relación con los precios de los productos de las explotaciones agrarias en la provincia argentina de Entre Ríos entre mediados y finales del siglo XIx, intentando comprender cómo funcionaron en un contexto que por momentos sufrió fuerte conflictividad: una grave crisis entre los años 1864-1873, y una violenta rebelión que habría de tener muy graves efectos políticos y económicos entre 1870 y 1876 . Esa dura coyuntura marcó asimismo un quiebre: a pesar de poseer Entre Ríos una de las áreas rurales más ricas de Argentina, y en un momento en que la producción agraria de sus vecinas crecía a tasas espectaculares, esta provincia se retrasó y declinó, perdiendo competitividad y posibilidades de captar parte consistente del flujo de inversiones y riqueza que atraía Argentina de ese entonces.

El objetivo es entender las causas de la evolución de los precios relativos de esos factores y su impacto en las condiciones operativas de las explotaciones rurales, así como, lateralmente, en sus tasas de ganancia y en las posibilidades de acumulación. Más allá de que la coyuntura de crisis económica y social impactó, el análisis en una perspectiva de largo plazo podrá mostrar si esos factores concurrieron a que la conflictividad escalara hasta niveles tan dramáticos. Por otro lado, es importante destacar que el estudio que realizamos busca comprender qué papel tuvo el factor trabajo en esa deriva, es decir, hasta qué punto en esa evolución el precio de las manos se diferenció o no del recorrido de los demás factores. Es conocida la mayor inelasticidad relativa del costo laboral; en la medida en que este se vio asimismo afectado por una difícil situación de guerra, 
ello seguramente resintió más aún la generación de oportunidades que esa economía podía ofrecer, y contrajo las expectativas de rentabilidad, reduciendo por tanto los fondos disponibles para inversiones que mejoraran la competitividad en una época en que la misma se tornaba crucial.

Es así necesario destacar que todo ello ocurrió en un momento clave por la necesidad de transformar la explotación rural en una empresa moderna. Desde mediados del siglo xix, el área actualmente conocida como región pampeana (y que abarca las provincias argentinas de Buenos Aires, Santa Fe, Entre Ríos y parte de Córdoba, así como otros territorios que se incorporarían al ámbito nacional con la conquista de los dominios aborígenes) se estaba comenzando a transformar en la fábrica mundial de alimentos y materias primas agrarias que llegaría a ser al final de esa centuria. En esa evolución surgieron núcleos nuevos en torno a nuevos productos, y los tradicionales cambiaron por completo. Desde la década de 1840, el área norte de Buenos Aires fue volcándose a la producción ovina moderna, que implicaba una transformación radical de instalaciones, rebaños, personal y rutinas productivas; desde 1850 comenzaron a concretarse colonias agrícolas formadas por inmigrantes extranjeros en Santa Fe y Entre Ríos, en sus inicios basadas en producción de granja diversificada, pero que pronto se especializarían en trigo y maíz para mercados regionales e internacionales; al mismo tiempo, en algunas zonas de Buenos Aires surgían las primeras cabañas orientadas a la producción de vacunos puros por cruza, buscando captar la demanda de carnes de calidad de los mercados urbanos y europeos. Y, por otro lado, la ampliación de la frontera con la progresiva conquista de las tierras otrora indígenas significaba lidiar con nuevos ambientes y nuevos desafíos productivos. Esa época de febriles transformaciones culminaría hacia 1910, cuando Argentina contara con una estructura productiva agraria similar, en cuanto a su nivel tecnológico, a las de mayor productividad del mundo; un mercado interior abastecido por las distintas producciones regionales, al cesar definitivamente las antiguas necesidades de importar harinas o trigos extranjeros, y un abanico de exportaciones relativamente diversificado, que abarcaba diferentes productos de origen agrícola y ganadero que cumplían con las pautas de calidad exigidas por los grandes centros de consumo mundial. Todas esas transformaciones implicaron gran despliegue de estrategias y experimentación, a menudo fallida, y, por consiguiente, fuertes inversiones de capital, a veces a pérdida. El mismo era naturalmente escaso en un país de economía aún pequeña, y en la cual el Estado, generalmente en déficit, y las rentables actividades de intermediación o de servicios, competían por esos fondos siempre insuficientes. Por lo tanto, la fuente primordial del capital de inversión radicaba en las propias empresas agrarias y en su rentabilidad; esto es, en la ecuación relativa de costo de factores, ya que se trata de una economía tomadora de precios en el mercado internacional 1

Así, durante la segunda mitad del siglo XIx, largas décadas durante las cuales la producción rural de las pampas argentinas había girado casi exclusivamente en torno a la ganadería vacuna extensiva, estaba, de una u otra manera, llegando a su fin. La inversión de capital se transformaba en pivote diferenciador: en casi toda el área se expandían formas productivas intensivas, que incorporaban procesos complejos, mano de obra especializada y maquinaria específica. El momento constituía un desafío; pero esa oportunidad en gran medida se perdió para los productores rurales de Entre Ríos, ya que sus resultados, al final del proceso, fueron mucho más magros que los de sus colegas de otras áreas cercanas. Ese fracaso, a menudo, ha sido atribuido a factores de tipo

\footnotetext{
${ }^{1}$ Todo indica que el todavía bajo precio relativo de la tierra por la oferta de nuevos territorios de frontera contribuía en muchos casos a reducir los costos operativos de las empresas de la pampa argentina; pero ello, por lógicas razones, no puede generalizarse. Algunos trabajos recientes han destacado esas diferencias, pero de todos modos la imagen general persiste (Djenderedjian, Bearzotti y Martirén, 2010, I, pp. 92 y ss.; 425 y ss.; Míguez, 2008, pp. 81 y ss.).
} 
ambiental, plasmados en dificultades para instaurar cambios tecnológicos acordes con la evolución del sector en determinadas regiones (véase Djenderedjian, 2008). Sin embargo, aun cuando es indudable que las mismas tuvieron su papel, ello no termina de justificar los problemas de esas áreas ancladas en formas de producción rural tradicionales para encarar cambios que el mismo fluir de los hechos hacía cada vez más imperiosos. Acecha aquí un fantasma, el del parasitismo rentista que suele atribuirse a algunos productores anclados en dominios extensivos gestionados bajo premisas tradicionales: si el problema no radicaba en los condicionantes ambientales, o estos no lo explicaban por entero, entonces la ineficacia en adaptar tecnología superadora de cuellos de botella se debió sin duda a la falta de espíritu innovador, y por tanto a falencias del sector empresario en tanto que tal. ${ }^{2}$

Sin embargo, al analizar la evolución de los precios relativos de los factores de producción las cosas se presentan distintas. Por un lado, porque las señales del mercado no necesariamente apoyaban un cambio tecnológico unívoco, aun tampoco en el sentido que este finalmente adoptó y, por otro, porque una vez tomadas las decisiones erróneas que culminaron en la pérdida de posiciones frente a los competidores, la acumulación de problemas propios de la coyuntura crítica impidió remontarlos de manera eficaz, provocando que el retraso se volviera estructural. Es decir, el menú de opciones que se presentaba a los productores rurales entrerrianos en determinado lugar y momento, a partir de sus costos y perspectivas de ganancia, fue cerrándose en forma acelerada, no permitiéndoles trascender la coyuntura con base suficiente como para encarar los necesarios cambios con los elementos imprescindibles. Las decisiones tomadas, así, y como es usual, sólo se mostraron erradas en el largo plazo; por tanto, no pueden atribuirse a simple aversión al riesgo.

El caso que aquí tratamos es útil entonces no sólo para completar de algún modo un panorama todavía insuficiente sobre las condiciones operativas de las explotaciones del área pampeana en una época de grandes transformaciones; también lo es para volver sobre un debate general, relativo a los límites estructurales del desarrollo agrario en países de escasa población y abundantes recursos naturales, que basan su estrategia de crecimiento en torno a la exportación de bienes primarios. Una de las premisas básicas de ese esquema es la necesidad de un extraordinario dinamismo del lado de la oferta, a fin de lidiar con problemas típicos del rubro, como la baja elasticidad del ingreso propia de los mercados de materias primas en los países receptores. En otras palabras, los aumentos de la productividad deben ser constantes; y no sólo en el sector exportador, si lo que se pretende es incrementar el bienestar de la población en general (Bulmer-Thomas, 2010, pp. 2030; Korol y Tandeter, 1999, pp. 19 y ss.). Los cereales y el ganado, productos que cubren tanto la demanda externa como las necesidades del mercado interno, son un ejemplo de la sinergia positiva generada en el conjunto de la economía por las mejoras de productividad en el sector de punta. Las mismas, lógicamente, desde cierto nivel sólo son posibles con una fuerte inversión de capital. Aun cuando el desempeño de Argentina en el marco de ese esquema haya sido modélico en la comparación con el resto de Latinoamérica, dentro de este país existieron sectores, y regiones, en las cuales lograr aumentos de productividad fue difícil, generando un crecimiento lento, o incluso estancamiento. Es lo que ocurrió en Entre Ríos durante la segunda mitad del siglo xIx, a la par de la construcción en Argentina de esa economía modélica; y puede incluso aventurarse que ese recorrido constituye un ominoso anticipo de los problemas que generarían a la economía nacional el posterior manejo de coyunturas adveras. Es en todo caso una advertencia acerca de problemas que no siempre merecieron la necesaria atención en los debates sobre el desarrollo basado en la

${ }^{2}$ El debate, en Argentina, ha sido muy intenso. Véanse, Sabato (1991) y Sesto (2005). 
exportación de bienes primarios; el análisis del sector productor entrerriano, por tanto, constituye un inmejorable punto de partida para retomar aquella vieja y no saldada discusión en torno a los condicionantes del crecimiento, y enfatizar hasta qué punto este último es producto de una larga serie de elementos, que incluyen no sólo los factores, las políticas y las estrategias de inversión, sino también cuestiones prosaicas, pero no menos importantes, como el peso de las coyunturas críticas y los cambios de orientación de los mercados. Las decisiones erróneas o las dificultades para la acumulación e inversión de capital, así, adquieren una dimensión substancial, y explican quizá mejor las causas del retraso relativo de unas economías respecto a otras ${ }^{3}$

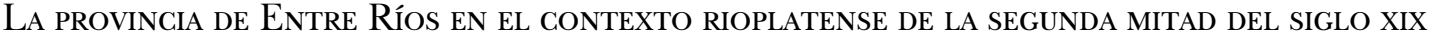

Dentro del ámbito rioplatense, Entre Ríos resulta un caso paradigmático: se trata de una porción significativa de la región pampeana, es decir, el corazón agrario de Argentina; si bien en el siglo XIX sus tierras no eran las de mejor calidad agronómica para la agricultura (por la alta humedad ambiente y la presencia devastadora de plagas de langosta), en la producción ganadera vacuna criolla, a campo abierto y con animales rústicos, no tenía rival. Pero, durante la primera mitad de esa centuria, su ingente riqueza fue destruida y vuelta a crear en el curso de las guerras de Independencia, y luego civiles, que ensangrentaron la región, y que tuvieron un campo de batalla privilegiado en su territorio. En ese contexto, los productores intentaron continuar generando negocios en medio del caos, logrando un notable éxito, patente sobre todo desde las décadas de 1830 y 1840. Un éxito tanto más sorprendente cuanto que el gran problema de esa economía, la escasez de mano de obra y de capital, se vio incluso agravado con el fin de la esclavitud y el reclutamiento de buena parte de los varones para servir en los ejércitos en marcha. Esta situación fue resuelta mediante la implementación de técnicas aún más extensivas de manejo del ganado, que compensaban la escasez de aquellos factores con la abundancia de tierras; y, sobre todo, con un cuidadoso y complejo sistema de disposición de la mano de obra, la cual fue disciplinada por los gobernantes a través del esfuerzo de guerra, haciéndola partícipe al mismo tiempo de un ethos colectivo mediante el cual, por un lado, se afirmaba un vigoroso sentimiento de pertenencia a la "comunidad" de los habitantes de la provincia, y, por otro, se distribuían premios y castigos por la participación en el conflicto bélico, los primeros, en especial, dosificando los permisos para acudir a la labor rural y otorgando autorizaciones para disponer del usufructo de parcelas de tierra a los soldados meritorios (Djenderedjian, 2008; Schmit, 2004). De esta forma, durante esas décadas convulsas la prosperidad no estuvo ausente de la economía entrerriana; hacia 1850 esta ya poseía la suficiente solidez como para pretender un lugar de privilegio en la constelación rioplatense, cediendo el primero sólo a Buenos Aires.

El tercer cuarto del siglo XIX fue para Entre Ríos una época de grandes cambios; la ganadería fue diversificándose hacia el ovino refinado y el vacuno de rodeo, aun cuando las mejoras genéticas fueron menos profundas que en Buenos Aires. Se expandieron los saladeros, manufacturas que posibilitaban un aprovechamiento intensivo del ganado, ya que de él se obtenían allí no sólo cueros curtidos sino también carne salada, ceniza que servía como abono, huesos, sebo, aceite y otros diversos productos (véase Macchi, 1971). Hubo avances sobre tierras marginales hacia el interior

\footnotetext{
${ }^{3}$ La diversidad misma de las regiones de frontera explica las bajas y erráticas tasas de ganancia de muchas empresas agrarias (Míguez, 1985); pero aun así la capacidad de remontar creativamente las coyunturas adversas sigue siendo un factor importante, rara vez considerado.
} 
provincial; en realidad de productividad decreciente, al encontrarse lejos de las vías de comunicación y no poseer, en general, buena dotación agronómica La población creció rápidamente, a una tasa anual de $4.2 \%$ entre 1856 y 1869, alcanzando 134271 habitantes, muchos de ellos extranjeros inmigrantes $\sqrt[5]{5}$ Se ensayaron también emprendimientos de colonización agrícola; pero este fenómeno, que transformó radicalmente a la provincia vecina de Santa Fe y luego a la de Córdoba, tuvo en Entre Ríos un impacto menor, por diversos problemas estructurales (Djenderedjian, 2008).

Todas esas transformaciones sólo tuvieron un correlato limitado en lo que respecta a la infraestructura: aun cuando los caminos interiores mejoraron, el tráfico fluvial continuó siendo, como tradicionalmente, el principal; ello ampliaba aún más la importancia de las áreas costeras en detrimento de las interiores, presionando aún más sobre el precio del factor tierra. La construcción de ferrocarriles, que hubieran podido cambiar esa ecuación, enfrentaba diversos obstáculos de orden natural, como la abundante presencia de cursos de agua, una alta humedad relativa y, a veces, fuertes desniveles del terreno. Así, no sorprende que, hacia 1876, de 2287 kilómetros de líneas ferroviarias en servicio o en construcción en toda Argentina, sólo 164 correspondieran a Entre Ríos, mucho menos que a cualquier otra provincia de su magnitud (Djenderedjian y Schmit, 2011, pp. 139-170). El retraso posteriormente se afianzó; si en 1876 Entre Ríos poseía por encima de $7 \%$ del total de la longitud de las líneas férreas de Argentina, en 1895, con 717.8 kilómetros sobre 14 799, su participación proporcional había bajado a menos de $5 \%$ (Argentina. Dirección de los Ferro-Carriles Nacionales, 1896, pp. 167-188).

\section{LOS CAMBIOS EN LA GANADERÍA ENTRERRIANA Y EL VALOR RELATIVO DE LA TIERRA}

El marco contradictorio que hemos reseñado en el apartado anterior indica que las peculiares características que a la provincia le habían permitido crecer parecen también haber estado luego entre los escollos que retrasaron la puesta a punto de su economía a los dictados de la nueva época. Un dato nos introducirá en el problema: para 1887 , sólo $0.42 \%$ de su rebaño vacuno era mestizo o fino, contra $36 \%$ en Buenos Aires.$^{6}$ Ese retraso sintetiza la pérdida de posiciones de la ganadería entrerriana: mientras hasta 1850 había generado fortunas y competido eficazmente con su similar bonaerense, tan sólo cuatro décadas más tarde esas ventajas se habían esfumado.

Pero a la vez, el valor relativo de la tierra había experimentado un cambio estructural. Con la nueva Constitución de 1853 y el nacimiento del Estado nacional argentino, las rentas aduaneras que manejaba cada provincia y que formaban sus principales recursos fiscales, fueron transferidas

\footnotetext{
${ }^{4}$ La frontera indígena había desaparecido en Entre Ríos a mediados del siglo xvII; por el contrario, en las otras provincias pampeanas existió hasta fines de la década de 1870. Los avances sobre la misma brindaron importantes estímulos a la producción rural ofreciendo bajos precios de la tierra, y enjugando con su venta los déficits fiscales.

${ }^{5} \mathrm{El}$ crecimiento luego se ralentizaría alrededor de $3 \%$ en las décadas de 1870 y 1880, alcanzando 295379 habitantes en 1895. De todos modos, la población rural parece haber crecido a un ritmo mayor, pasando de 78891 a 194141 habitantes entre 1869 y 1895 , esto es, alrededor de $3.5 \%$ anual. Fuente (1872) y Fuente, Carrasco y Martínez (1898, p. 2).

${ }^{6} \mathrm{El}$ proceso de mestización del ganado vacuno criollo comenzó ya en la década de 1820, con la introducción desde Inglaterra del primer reproductor Shorthorn (raza entonces llamada Durham). Pero recién adquirió entidad después de 1857, en manos de una vanguardia de productores bonaerenses que experimentaron en torno a diversos problemas ligados a ello, en esencia, la adaptabilidad al ambiente pampeano, el cambio de la base de pasturas, las estrategias para manejar las cruzas, la formación de mano de obra especializada y la construcción de infraestructuras. Véase Sesto (2005).
} 
a la nación $\sqrt[7]{ }$ Ello implicó la búsqueda de nuevas fuentes de ingreso e imposición. La disponible y lógica era la tierra, ya que existían grandes superficies cuyo estatus legal podía ser reclamado por el fisco provincial y por tanto ser a la postre por este arrendadas o vendidas; y, por otro lado, conociendo, midiendo y tasando en forma efectiva las propiedades particulares, podría conformarse una base tributaria sobre la cual ejercer presión recaudatoria. Pero eso implicaba un cambio radical en los derechos de propiedad, hasta entonces apenas respaldados por diversos instrumentos formales e informales, así como por prácticas consuetudinarias y acuerdos de palabra, tanto entre particulares como entre estos y el Estado. Antes de 1860, ningún instrumento formal, en rigor, garantizaba la propiedad plena ${ }^{8}$ Los acuerdos entre particulares (trabados sobre dominios tan inseguros) no habían tampoco sido en general protocolizados 9 Así, primaban derechos consuetudinarios y la capacidad de demostrar ocupación a lo largo del tiempo; esos derechos estaban asimismo respaldados por la larga tolerancia de las autoridades, e incluso podían alegarse como justa compensación por los servicios militares prestados por esos ocupantes (véase Schmit, 2004).

Pero desde 1860 comenzaron a transformarse radicalmente las formas de acceso a la tierra. Se dictó una serie de leyes restringiendo el dominio consuetudinario; se constituyó un registro catastral, y se puso en arrendamiento a todas las tierras consideradas públicas aun cuando estuvieran pobladas, tanto fueran las de quienes contaran con títulos precarios como las de los meros ocupantes ${ }^{10}$ Las quejas se multiplicaron, en particular, de soldados que creían poseer sus tierras a perpetuidad en pago de servicios prestados, así como denuncias sobre problemas de los ocupantes para demostrar sus derechos ${ }^{11}$ El Estado se hizo de la propiedad eminente de grandes superficies, las cuales arrendó a sus ocupantes; pero la resistencia al pago de los mismos parece haber sido generalizada, debiéndose intimar fuertemente a los morosos, lo que muestra de paso cuánto habían cambiado las cosas ${ }^{12}$ Posteriormente, se pusieron en venta cantidades crecientes de esas

\footnotetext{
${ }^{7}$ La creación del Estado nacional implicó la absorción por él de las rentas aduaneras de todas las provincias, y la abolición de las aduanas interiores. Con ello, las provincias perdieron sus fuentes de financiamiento. Sobre el proceso véase Gelman (2011, pp. 29-35).

${ }^{8}$ Son ilustrativos al respecto los largos y complejos expedientes formados para probar derechos de dominio conservados en Gobierno, serie VIII, en Archivo Histórico y Administrativo de Entre Ríos, Paraná (en adelante, AHAER). Los títulos podían incluir permisos otorgados por el cabildo local, antiguos títulos de merced, procesos de compra al fisco por composición, con información de testigos; y aun simples notas emitidas por alguna autoridad. Es decir, no estaban en general respaldados por registro notarial ni catastro.

${ }^{9}$ Los protocolos notariales anteriores a 1860 han desaparecido, salvo algunos libros sueltos; en todo caso, los existentes muestran que la mayor parte de las transacciones registradas son de carácter urbano, lo cual sugiere el peso mayoritario de acuerdos informales en lo que respecta a contratos sobre tierra rural, algo que a su vez es confirmado por la escasa presencia de copias de instrumentos jurídicos formales en los expedientes destinados a probar dominio que se comenzaron a recopilar luego de 1860.

${ }^{10}$ Argentina. Provincia de Entre Ríos (1875 y ss., pp. 202-215). Se exigió asimismo la presentación de los títulos precarios existentes, para resolver sobre su validez.

${ }^{11}$ Véase Reinaldo Sillar a los ministros generales, Gualeguaychú, 8 de agosto de 1862, Gobierno, viII, caja 5A, leg. 17, en AHAER. En otra nota del 18 de octubre, Reinaldo Sillar insiste en las dificultades de las personas pobres para acreditar y registrar sus títulos. El legajo 19 de esa serie incluye notas de otro departamento por los mismos asuntos, y los ejemplos podrían multiplicarse. La correspondencia del gobernador Justo J. de Urquiza con diversos funcionarios y comandantes registra situaciones similares, véanse, Isaías Toledo a Justo J. Urquiza, Yeruá (1 de enero de 1864); Cesario Dominguez al mismo, Concordia (18 de abril de 1861). Archivo Urquiza, legs. 1723, 1686. Archivo General de la Nación (en adelante AGN).

${ }^{12}$ La ley fijaba un arrendamiento anual de 50 pesos por legua cuadrada en campos de pastoreo, tanto para los poseedores con título legal como para los meros ocupantes, hasta tanto se dictara la ley del ramo; y no implicaba reconocimiento de derechos posesorios. Para 1871, con el sistema funcionando hacía ya una década, los ingresos por
} 
superficies fiscales, con un precio mínimo de 3000 pesos en oro por legua cuadrada, a pagar a un máximo de dos años; aumentado en 1866 a 3150 pesos, de todos modos condiciones muy onerosas para una buena parte de los ocupantes ${ }^{13}$ Las mensuras para conformar el registro de títulos suscitaron fuertes tensiones: en 1866 se expidió una circular en la que se reconocía que los derechos de los poseedores de campos de pastoreo eran repetidamente atropellados por las mismas. 14 En resumen, el periodo 1860-1869 está jalonado por el dictado de más de 30 normas legales relativas a la tierra, contra sólo tres en la década anterior; y, mucho más importante, esas normas fueron por primera vez aplicadas, a la inversa de lo que había ocurrido anteriormente con otros intentos de regularizar los catastros. A ello se sumaba la difusión del alambrado, que contribuía a delimitar eficazmente los campos más extensos. Todo ello, como es lógico, implicaba también mayores costos.

Es importante tener en cuenta que ese proceso ocurrió en un contexto sin frontera abierta. La inexistencia de la misma en Entre Ríos, como se ha dicho, diferenciaba a esta provincia de las demás del área pampeana; y esa inexistencia imponía un límite inferior al costo del factor tierra, ya que no era posible allí ampliar constantemente la producción sobre áreas "nuevas" conquistadas a los aborígenes. En ese contexto, la producción ganadera extensiva necesariamente debía ampliarse sobre áreas ya ocupadas, o marginales a las mismas; por tanto, de menor rendimiento o más caras que las disponibles para esas mismas actividades en otras provincias cercanas. A la vez, la extensividad (y escaso o nulo aumento de productividad del vacuno por las restricciones a la inversión que suponían los mayores costos operativos) limitaba el rendimiento del factor trabajo; y a ello se sumaba la presión derivada de la ampliación del stock de ovinos, los cuales, si bien constituían una alternativa algo más intensiva a los vacunos, eran del mismo modo menos competitivos que los bonaerenses, con mayor rendimiento por unidad y menores costos de acceso al mercado.

Así, en Entre Ríos ambos rubros productivos convivían en un espacio productivo limitado; si a ello le sumamos la presión gubernamental por la regularización de tenencias fundiarias, no puede sorprender que, para 1888, el precio promedio de la hectárea fuera en Entre Ríos largamente superior al de todas las demás provincias pampeanas, siendo sólo superado (y no mucho) por Buenos Aires, cuyas tierras eran de alta calidad agronómica. ${ }^{15}$ Es así evidente que el costo de la tierra rural

arrendamiento de tierras públicas apenas alcanzaban $15 \%$ del total. Según los informantes, la escasez de la recaudación se debía, entre otras cosas, a "la necesidad de tomar datos sobre deudores de arrendamientos, que no existían en las receptorías", con lo que asumían la falta de algo tan básico como un padrón general. Argentina. Provincia de Entre Ríos (1872, pp. 122-129); Argentina. Provincia de Entre Ríos (1875 y ss. viI, pp. 209 y ss., viII, p. 356).

${ }^{13} \mathrm{El}$ promedio de la riqueza rural individual declarada en el departamento Paraná en 1862-1863 sólo alcanzaba a unos 700 pesos fuertes (moneda prácticamente equivalente al peso oro en que se habían establecido los ya aludidos precios de la tierra fiscal). El peso boliviano, de $20 \mathrm{gr}$ (conocido por de 400 granos) y 900 milésimos, de plata feble, corría como moneda local en el interior argentino hasta la reforma monetaria de 1881, y aun después de ella en muchos casos. Fue valuado a 65 y 79 centavos de peso fuerte (antiguamente el peso de plata español, pero desde 1863 de oro) entre 1874 y 1879 tanto por el Banco de la Provincia de Buenos Aires como por el Provincial de Santa Fe, véase Álvarez (1929, pp. 110-118). El peso fuerte oro fue moneda de cuenta para la administración pública nacional, y fue asimismo adoptado por varias administraciones provinciales, como fue el caso entrerriano desde 1867. Los datos sobre riqueza individual en Djenderedjian y Schmit (2011); por la misma época se había fijado en 1000 pesos fuertes el valor mínimo de la legua cuadrada de tierra fiscal en Santa Fe, lo que marca la dimensión de un fenómeno que analizaremos después a detalle: el gran aumento en el valor de la tierra entrerriana (Napp, 1876, p. 429).

${ }^{14}$ En 1864 se había resuelto reservar los sobrantes de las mensuras para ser adjudicados a los ocupantes de terrenos particulares, lo que constituye otra muestra de la conflictiva situación de estos. Véase Ruiz (1896, t. I, pp. 134 y ss., especialmente p. 158).

${ }^{15}$ Según relevamientos que incluyeron precios de mercado, la hectárea valía en Entre Ríos 20 pesos moneda nacional; en Buenos Aires, 30, mientras que, en Santa Fe y Córdoba, 7.66 y 6.5, respectivamente. Latzina (1889, p. 80). 
había crecido más que la rentabilidad esperada de la misma, o al menos había limitado al mínimo la rentabilidad, y constreñido por ello el capital disponible para reinversión ${ }^{16}$ El crecimiento de los rebaños y la falta de tierras alternativas motivaba dura lucha por los pastos; en la segunda mitad de la década de 1860 algunos grandes propietarios rurales del centro sur provincial parecen haberse visto asediados por intrusos que, una vez instalados, estaban incluso dispuestos a pagar arriendo, pero no a irse, pretextando las importantes pérdidas en sus rebaños que tal cambio provocaría $\sqrt{17}$

Es importante retener todo esto para comprender dos cosas: la primera, la alta conflictividad que estallaría en 1870; la segunda, el creciente peso de la tierra como costo de producción. En efecto, luego de mucho tiempo de ser un factor de escaso o nulo valor de cambio, la tierra comenzó a convertirse en un elemento de cada vez mayor peso en los inventarios de los productores rurales (véase cuadro 1). Un estudio sobre los mismos muestra con claridad ese proceso.

En el periodo 1832-1859, la tierra sólo dio cuenta de $11 \%$ del valor total de los inventarios entrerrianos. Ese guarismo resulta muy similar (e incluso menor) al que tradicionalmente había existido en las explotaciones agrarias rioplatenses hasta la segunda década del siglo xIX ${ }^{18}$ Es decir, en Entre Ríos se prolongó la disponibilidad de tierras baratas hasta promediar el siglo, algo que no ocurrió en su vecina Buenos Aires. Pero en los años siguientes las cosas comenzarán a cambiar en forma acelerada. En la década de 1860 la inversión en tierras sube en promedio a $27 \%$ del valor total de los inventarios; mientras que en la de 1870 ya es de $45 \%$. De modo que en poco tiempo se quebró la antigua ecuación en la que la tierra compensaba el alto costo laboral mediante aumentos en la escala productiva. Las mayores exigencias de inversión de capital que implicaba esa rápida valorización de la tierra fueron expuestas en un artículo publicado en 1888, que enfatizaba los cambios en la demanda de ganado, orientados desde hacía años hacia animales de mayor calidad.

La cría de ganados ordinarios a la antigua usanza produce sólo cuando los campos se mantienen a un bajo precio; aun así que el valor de la tierra sube hasta alcanzar a los precios a que ha llegado en esta provincia, ya no da ni un mediocre interés sobre el capital que representa; y entonces hasta los más retardatarios, vense obligados a cambiar de método [...] Antes del año 1880 las estancias conservaban en su casi totalidad su fisonomía primitiva... (Argentina. Departamento Nacional de Agricultura, 1888).

\section{¿Qué ocurrió en tanto con el costo del trabajo?}

\footnotetext{
${ }^{16}$ Uno de los problemas que generaba la ganadería criolla extensiva en un contexto de escasez de capital era la búsqueda constante de más tierra para acomodar las ampliaciones del stock. Mientras la ocupación del espacio fue precaria, la abundancia de buenas tierras mitigaba los altos costos de la mano de obra y el capital; pero cuando aquellas comenzaron a escasear, la mayor demanda terminó por impulsar los precios, afectando la tasa de ganancia. Contamos con cuentas bastante detalladas de una estancia entre 1862 y 1866; en esa época de bonanza, la tasa de ganancia anual promedio sólo llegó a $3.5 \%$. El costo del arrendamiento de la tierra por sí solo era similar al total de los gastos operativos (salarios de peones, amortización de equipamiento, insumos, etc.). Es de notar que, de acuerdo con la superficie y el stock disponible, la carga ganadera en esa estancia era de apenas 0.15 vacunos por hectárea, índice en esencia similar al de otros establecimientos de inicios del siglo, mientras que en Buenos Aires era de 0.39 a 0.49. Testamentarias, caja 15, Maria F. Bustamante de Beades, en AHAER. El dato de Buenos Aires en Jurado (1875). La reducción a unidad ganadera (vacuno) se efectuó según el criterio del censo agropecuario de 1881; un vacuno equivale a un cerdo; ocho ovejas; o 0.8 equinos, mulares o burros (Fuente, 1883, p. LVIII).

${ }^{17} \mathrm{Al}$ menos eso es lo que ocurrió en la estancia de Mateo García de Zúñiga, cercana a Gualeguaychú. Véase correspondencia pasiva de este y su esposa, legs. 8-9. Archivo del Instituto del Profesorado Osvaldo Magnasco.

${ }^{18}$ Garavaglia (1999) calcula $13 \%$ hasta 1815 en Buenos Aires; para el periodo 1816-1852, en cambio, la proporción de la tierra pasa a $21 \%$. Gelman y Santilli (2013) han detectado creciente dificultad en el acceso a la tierra en Buenos Aires entre 1820 y 1867.
} 
CUADRO 1. DISTRIBUCIÓN DE LA INVERSIÓN RURAL, ENTRE RÍOS, 1832-1879 (EN PORCENTAJES SOBRE EL VALOR TOTAL)

\begin{tabular}{rrrrr}
\hline & Inmuebles & Ganado & Mejoras & $\begin{array}{c}\text { Resto activos } \\
\text { rurales }\end{array}$ \\
\hline $1832-1849$ & 11 & 71 & 7 & 10 \\
$1850-1859$ & 11 & 77 & 4 & 8 \\
$1860-1869$ & 27 & 62 & 7 & 4 \\
$1870-1879$ & 45 & 42 & 11 & 3 \\
\hline
\end{tabular}

Fuente: Djenderedjian (2013, p. 181).

\section{LA EVOLUCIÓN DE LOS SALARIOS RURALES}

Para obtener la serie de salarios rurales, hemos recurrido a los registros de un grupo de empresas agrarias pertenecientes a Justo José de Urquiza, el principal hacendado de la provincia, y además hombre político de primer orden en ella y aun en Argentina (del cual llegó a ser presidente). Este personaje, hijo de un comandante militar y hacendado de tiempos coloniales, fue construyendo un impresionante patrimonio que abarcaba, al momento de su asesinato en 1870, una amplísima diversidad de establecimientos, fundamentalmente ganaderos, situados en diversos puntos de la provincia ${ }^{19}$ Esa fortuna, para ese año, sumaba 272 leguas cuadradas de campos, es decir más de 734400 hectáreas, en las que prosperaba un enorme plantel de ganado vacuno y ovino. Además, poseía un numeroso y diversificado conjunto de inversiones que incluyeron saladeros, propiedades urbanas, acciones en bancos, empresas de ferrocarril y de producción azucarera, así como títulos públicos. En su testamentaria su fortuna fue valuada en un total de 5436923 pesos bolivianos, que se repartían en $69.3 \%$ en bienes rurales, $8.1 \%$ en propiedades urbanas, $2.2 \%$ en bienes industriales y 20.4 \% en títulos y acciones, lo que lo constituía en uno de los propietarios más acaudalados del Río de la Plata (véase Schmit y Djenderedjian, 2006, pp. 7-49).

Luego de su fallecimiento la administración continuó siendo llevada por sus herederos, encabezados por su viuda, bajo las mismas pautas y con el mismo personal empleadas anteriormente, por lo que los registros son homogéneos. Los manuscritos se encuentran archivados en lo que fue la residencia de Urquiza, el llamado Palacio San José, en un área rural en las cercanías de Concepción del Uruguay (en adelante APSJ). La práctica administrativa (en vigor al menos desde 1846, aunque sólo se generalizaría a todos los establecimientos en los años sucesivos) consistía en que, desde cada uno de los establecimientos rurales, los mayordomos o encargados confeccionaban listas mensuales de los salarios devengados, en las cuales figuraban usualmente los nombres de los empleados, sus categorías, el monto mensual acordado y a veces lo pagado en forma adelantada, a fin de que el total de la lista fuera suplido en dinero desde el escritorio central. Esos registros se volcaban luego a libros de contabilidad, ya fuera nominalmente o en forma resumida. Hemos utilizado ambos tipos de registros, tomando todos los disponibles para cada mes y año entre $1846 \mathrm{y}$

\footnotetext{
${ }^{19}$ Adelantemos aquí que, con el asesinato de Urquiza en 1870 , se inicia la guerra civil que ensangrentará a la provincia durante años.
} 
1875, obviamente depurándolos de posibles repeticiones ${ }^{20}$ De cada listado de personal tomamos los salarios mensuales de la categoría más baja (peón-puestero, correspondientes respectivamente a los trabajadores empleados en tareas generales y a los encargados del cuidado del ganado). Se trata de los montos en dinero percibidos directamente por los trabajadores, a quienes además se proveía de alimento y alojamiento, los cuales no han sido tomados en cuenta en nuestra serie. Entre los salarios pagados a miembros de la categoría general peón-puestero existían a menudo fuertes diferencias, debidas fundamentalmente a la edad de los trabajadores (los muchachos de hasta catorce o quince años, por ejemplo, cobraban alrededor de la mitad de los adultos). Esos casos extemporáneos fueron incluidos en el cálculo, a fin de reflejar más adecuadamente la nómina y el gasto total; de todos modos, se trata siempre de una minoría de individuos. Asimismo, si un trabajador determinado pasaba temporal o definitivamente a categorías superiores a las de peónpuestero, o cobraba por tareas a destajo, o por cualquier razón no pudiera ser ya encuadrado en el espectro que definimos, se lo descartó.

A fin de corregir las distorsiones debidas a la amplitud del rango de las remuneraciones, elaboramos el promedio de la suma algebraica de todos los salarios pagados mensualmente en la categoría. A menudo, la lista total mensual abarcaba los salarios de más de 100 personas, pero en otros casos la cifra descendía hasta 20 o 30, dependiendo de la cantidad de establecimientos cuyos datos han llegado a nosotros. De esa forma, se minimizó el peso de los salarios inferiores o superiores a la media, puesto que los mismos sólo constituyeron en todos los meses una parte menor de la nómina, la cual resultaba determinada por la abundancia de casos situados dentro del rango de lo que, en cada periodo, se podía considerar el salario corriente para esas tareas a ser pagado a un hombre adulto joven sin falencias de formación ni premios determinados por experiencia o responsabilidades adquiridas. Como forma de control, establecimos las modas mensuales, las cuales coincidieron bastante estrechamente con la serie elaborada, mostrando así su solidez. Las diferencias en los niveles salariales de uno a otro establecimiento no fueron significativas, aun entre los situados a respetable distancia, incluso varios cientos de kilómetros; los testimonios de la época señalan que existía una gran movilidad y circulación de información dentro del territorio, por lo que resultaba muy difícil ofrecer salarios más bajos que la media provincial sin tener que soportar caídas en la oferta laboral ${ }^{21}$ No se detectaron diferencias significativas determinadas por el hecho de que las tareas se desempeñasen con rebaños de ganado vacuno u ovino; por otro lado, sí hubo diferencias de magnitud en los casos en que se trataba de empleados de origen extranjero (lo cual se pudo detectar fácilmente por sus apellidos). Estos últimos fueron descartados, ya que, aun cuando a menudo la fuente no lo especifica, se trataba de empleados especializados en el tratamiento de majadas de sangre pura, o vinculados a tareas que requerían pericia técnica particular. Tampoco, obviamente, se tuvieron en cuenta aquellos casos en que se especificaban tareas

\footnotetext{
${ }^{20}$ Vida de Urquiza y sus ascendientes (1773-1870), en fondo Justo José de Urquiza, y el periodo 1870-1896, en fondo Dolores Costa. En cada fondo, las secciones establecimientos agropecuarios; administración central; Palacio San José, y actividades económicas diversas concentran la documentación consultada. Sería imposible citar aquí todas las cajas, carpetas y libros contables de cada una de esas secciones que hemos utilizado.

21 "Precios esquila. He estado en Gualeguaychu y Campos Floridos y por todas partes han pagado 18 y 20 ps. por mes dando tijeras los esquiladores, y yo he puesto el precio de 16 ps. dando [el establecimiento las] tijeras, y una vez que muchos esquiladores supieron este precio se me fueron muchos...” Alejandrino Martínez a don José Ballestrin, San Miguel, 23 de octubre de 1871. Fondo Dolores Costa, caja 815, carpeta 180, en APSJ. San Miguel se encontraba cerca de Nogoyá, a unos $200 \mathrm{~km}$ de Gualeguaychú. Por otro lado, los salarios pagados por el estado provincial en los distintos departamentos de la provincia, a las mismas categorías de empleados, fluctúan siempre dentro de un rango máximo de 6 a 9 por ciento.
} 
determinadas, no relacionadas con el cuidado rutinario del ganado mayor (quinteros, cocineros, carretilleros, boyeros, carpinteros, etc.) ni los propios de épocas de zafra lanera, y otras tareas estacionales o eventuales, para las cuales los salarios eran más altos que los del personal permanente (esquiladores, agarradores, trasquiladores, envellonadores, aguateros, afiladores, curanderos, lateros, etcétera) 22

Además, se elaboró otra serie a partir de los salarios contemplados en el presupuesto anual de gastos del estado provincial, los cuales figuran en forma más o menos regular desde 1861; nuestra serie tomó los datos disponibles hasta 1875. Hemos seleccionado los salarios a pagar a soldados, cabos y sargentos de las comisarías de campaña hasta 1870; y, desde 1871, los correspondientes a guardias, cabos y sargentos de las guardias de seguridad con sede en cada uno de los departamentos provinciales. En ambos casos se trata de promedios de los salarios individuales de las tres categorías para cada departamento, los cuales fueron luego a su vez promediados. No existen diferencias significativas entre lo presupuestado para unos y otros puntos de la provincia. Las comisarías de campaña y las guardias de seguridad se encontraban en cada una de las capitales departamentales y en la capital provincial, cumpliendo la tarea de mantener el orden interior, para lo cual ejercían también jurisdicción sobre las campañas respectivas. El cambio entre 1870 y 1871 responde a que, a partir de este último año, las guardias de seguridad reemplazan en nuestra serie a las comisarías (que, en los presupuestos, sin embargo, reaparecen en 1874 y 1875 luego de dos años de supresión, sin que por ello sean eliminadas las guardias de seguridad) y, más importante aún, para las categorías de tropa se presupuesta rancho (es decir alimentos), a partir de 1871 y en forma desagregada del salario. De modo que tuvimos que dividir la serie en dos, una incorporando el rancho y otra sin él. Anterior a 1871 no hay en los presupuestos referencias a gasto en alimento para los soldados, pero probablemente el mismo se supliera mediante envíos de ganado desde los corrales y estancias del estado. El valor del rancho aumenta gradualmente, desde tres pesos fuertes por mes y por persona en 1871 hasta cinco en 1875; pero puesto que no conocemos cuál era su composición, y de que se trata además de montos globales, a cubrir por contrato, no puede considerarse un indicio del costo real de los alimentos.

Los salarios rurales privados (obtenidos a partir de los registros del APSJ) están en pesos bolivianos, manteniéndose esa moneda en los pagos incluso hasta muy tarde ${ }^{23}$ En tanto, los salarios de los presupuestos provinciales pasan a contabilizarse en pesos fuertes oro a partir de 1867, por lo que fue necesario convertirlos a pesos bolivianos a fin de conformar series homogéneas ${ }^{24}$ Es menester aclarar que, desde inicios de la década de 1860, circulaba en Entre Ríos papel moneda emitido por varias casas comerciales o bancos privados; sin embargo, no parece que el monto de esas emisiones afectara sustancialmente la circulación monetaria, toda vez que las mismas sólo sumaban, para 1880, 15000 pesos bolivianos y 11000 pesos fuertes. La misma fuente calculaba ese año en 4000000 de pesos bolivianos el circulante metálico en manos de los ciudadanos en el

\footnotetext{
${ }^{22}$ En general, esas tareas se pagaban a destajo o a jornal.

${ }^{23}$ Todavía los registros de pago de finales de 1882 continuaban siendo llevados en pesos bolivianos. Véase Relación del personal ocupado en las Estancias..., Bella Vista, noviembre de 1882. Fondo Dolores Costa, caja 47, carpeta 117, en APSJ.

${ }^{24}$ Véase nota 18. La relación de valor entre plata y oro se mantuvo dentro del rango 1:15.5/16 desde 1800 hasta el abandono del patrón plata por parte de Estados Unidos en 1876; de hecho, según los datos transcritos por Officer y Williamson (2018), en 1874 la relación cambió a 16.16, aumentando al año siguiente a 16.64 y el posterior a 17.75. A fin de convertir nuestra serie de salarios oficiales en pesos fuertes oro a pesos bolivianos plata utilizamos las tablas de conversión elaboradas por Juan Martirén para la vecina provincia de Santa Fe y la ciudad de Buenos Aires, agradeciéndole por su gentileza.
} 
interior de Argentina, y unos 2335000 el efectivo en los bancos. ${ }^{25}$ Lo que podríamos denominar M0, entonces, sumaría a esa fecha 6335000 pesos, de los cuales puede estimarse que corresponderían a Entre Ríos (de acuerdo con su población y desarrollo económico) al menos 700000 pesos ${ }^{26}$ Todo ello indica que no hubo a lo largo del periodo cambios sustanciales en la composición del efectivo recibido por los trabajadores, y por tanto tampoco pérdidas de parte del valor en metálico de esos salarios, si es que de estos alguna porción se hubiera pagado en papel, susceptible de depreciación contra la moneda dura (véase gráfica 1) 27

Debemos tener en cuenta que, a partir de 1864, se producen diversos acontecimientos que afectaron de manera sustancial la economía de la provincia. En primer lugar, la coyuntura crítica 1864-1873: los precios de los productos ganaderos de exportación se derrumban, viéndose afectados tanto los mercados de la lana como los del cuero vacuno y el tasajo (véase Djenderedjian, 2013, pp. 169-196). En segundo lugar, en 1865 se desata la guerra del Paraguay, que durará hasta 1870 , afectando particularmente a la provincia por su cercanía al teatro del conflicto y por la recurrente oposición de buena parte de los soldados a ser enviados al frente. En tercer lugar, debe mencionarse la durísima guerra civil desatada en 1870, y que, aplastada a inicios del año siguiente por fuerzas nacionales luego de una sangrienta campaña, volvería a estallar con intermitencias hasta la derrota definitiva de su principal caudillo, Ricardo López Jordán, en 1876 (véase Reula, 1969, t. II, pp. 32 y ss.).

No es este el lugar para desarrollar esos tres acontecimientos; sólo queremos destacar la fuerte inelasticidad del salario rural privado, que, a pesar de esas circunstancias adversas, no se vio mayormente impactado. Sí lo fueron en cambio los salarios gubernamentales (véase gráfica 1): luego de mantenerse largo tiempo en el mismo rango que los privados, aumentan sustancialmente (casi $30 \%$ ) durante el primer año de la guerra del Paraguay, sosteniéndose en esos niveles hasta el final de la misma; si bien en los años posteriores (marcados ahora por la contienda civil) los salarios en dinero efectivamente percibido descienden, en realidad las prestaciones recibidas continúan en los mismos niveles, en parte bajo la forma de alimentos.

Es evidente que los niveles salariales pagados por el Estado no influyeron tampoco demasiado en los privados; en todo caso, recién parecen haberlo hecho una vez conjurados los problemas políticos. No es del todo sorprendente, ya que, si bien la movilización por la guerra debió significar una drástica merma en la oferta laboral, la coincidente crisis económica compensó esa merma con una también menor demanda. Pero ello no significa que, para los empresarios, los costos laborales no aumentaran: los pagos por determinados servicios o por ciertas capacidades sufrieron en esos años aumentos muy consistentes. No hemos incluido la serie de salarios de categorías superiores (capataz, mayordomo, encargado) por razones de espacio; pero la misma, aun exhibiendo hasta inicios de la década de 1860 una trayectoria similar a la de peones-puesteros, posee sin embargo una volatilidad mayor, que se acentúa aún más desde entonces. En los momentos más álgidos de la crisis, algunos casos llegan a ser sorprendentes: Ricardo Belson, encargado de la estancia Armonía, ganaba 40 pesos por mes hasta junio de 1870; a partir de julio, su sueldo se elevará a 100 pesos mensuales. Alejandro Martínez, encargado de la estancia El Potrero, tendrá desde agosto de 1870

\footnotetext{
${ }^{25}$ Es decir, en el territorio nacional sin incluir la ciudad y provincia de Buenos Aires (Agote, 1881, t. I, pp. 209 y ss).

${ }^{26}$ Para 1869 Entre Ríos concentraba 10 \% de la población de Argentina excluyendo Buenos Aires y la Capital. Pero su desarrollo económico y comercial eran superiores al de la mayoría del resto de las provincias, por lo que el circulante metálico per cápita allí debía ser mayor que en estas últimas.

${ }^{27}$ En las cuentas nunca se indica qué parte de los salarios se pagará en papel.
} 


\section{GRÁFICA 1. SALARIOS RURALES PRIVADOS Y SALARIOS MILITARES OFICIALES, POR MES. ENTRE RÍOS, 1846-1875 (EN PESOS BOLIVIANOS DE PLATA)}

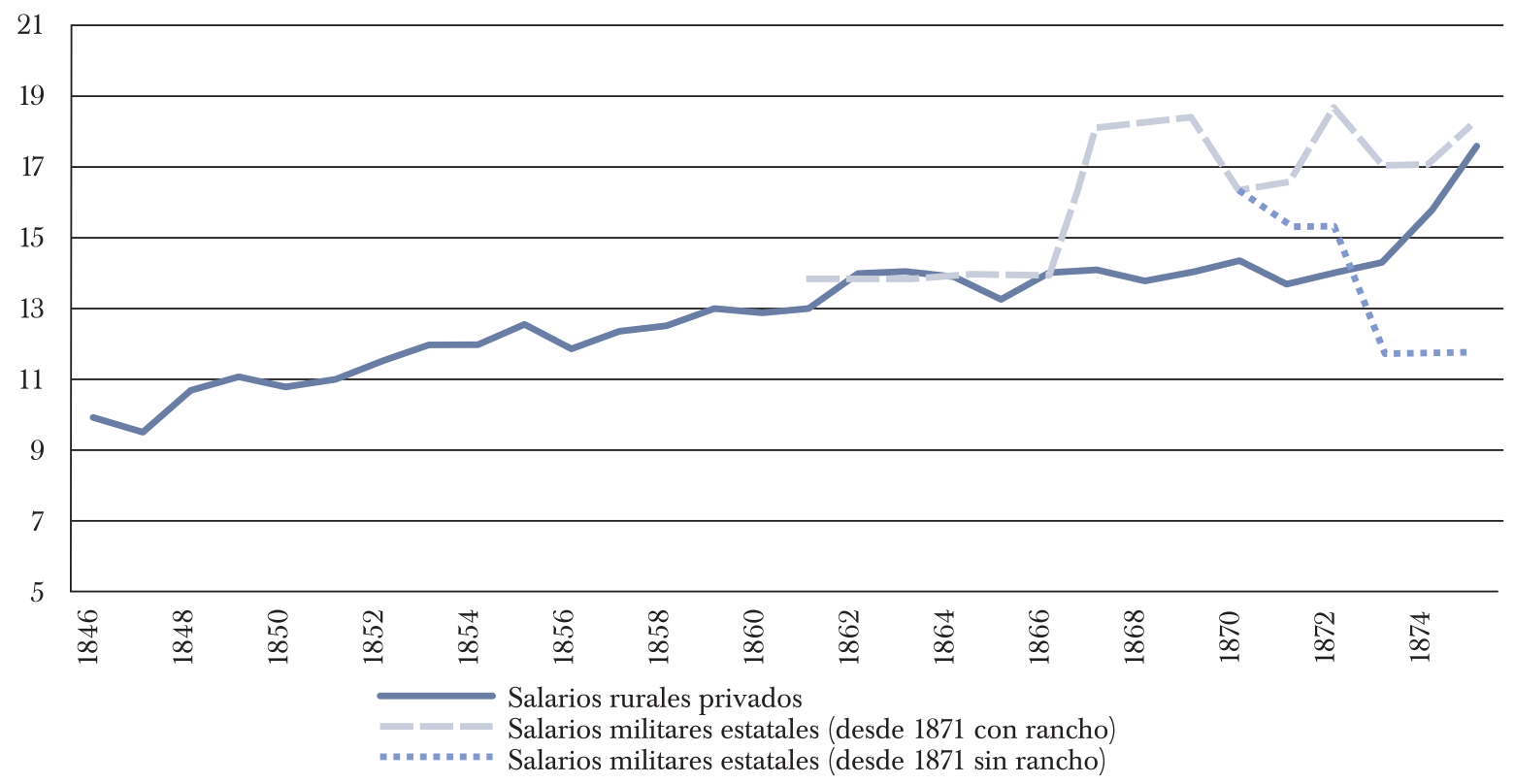

Nota: salarios rurales privados corresponden al promedio pagado mensualmente en las categorías peón-puestero según figura en los listados de personal de los diferentes establecimientos productivos. Los salarios militares están tomados de los presupuestos oficiales de la provincia para cada año; hasta 1870 corresponden al promedio mensual pagado a soldados, cabos y sargentos de las comisarías de campaña, distribuidas por toda la provincia. Desde 1871, a guardias, cabos y sargentos de las guardias de seguridad, distribuidas también en los distintos departamentos. Desde ese año, además, se provee rancho, contabilizado y pagado aparte. La serie por tanto se divide, a fin de presentar el salario con y sin el rancho, ya que en rigor este no formaba parte del pago monetario, y además va adquiriendo mayor entidad con el paso del tiempo.

Fuentes: Salarios rurales privados, fondo Justo José de Urquiza y fondo Dolores Costa, series Establecimientos Agropecuarios, y otras, varias cajas y carpetas, listados de personal varios. Salarios militares estatales en Argentina. Provincia de Entre Ríos (1875-1877, tt. IX y ss.), en APSJ.

un astronómico salario de 200 pesos ${ }^{28}$ Se trata de una coyuntura muy compleja: en medio de la guerra civil, la retención de los cuadros dirigentes por parte de la administración de los herederos de Urquiza no debe de haber sido algo sencillo 29 El momento exigía además un know how especializado que se volvía cada vez más imprescindible y necesario para manejar los crecientes rebaños mestizados; ello en buena parte podría explicar también la creciente diferenciación en los sueldos de las categorías intermedias y bajas, y la aparición y difusión de los patronímicos de origen germánico y sajón, evidentemente ligados al cuidado de reproductores importados y a la organización y administración de majadas con cruza.

${ }^{28}$ Fondo Dolores Costa, Establecimientos agropecuarios, caja 819, carpeta 490, Lista de sueldos de los puesteros..., Establecimientos Armonía y Mercedes (Gualeguay); carpeta 734, Lista del Establecimiento Potrero y sus dependencias, agosto de 1871, en APSJ. El Potrero era una inmensa estancia ubicada entre Gualeguaychú y Concepción.

${ }^{29} \mathrm{El}$ asesinato de Urquiza marcó el estallido de la guerra civil. Por tanto, si bien sus establecimientos no parecen haber sufrido más que otros por el conflicto, de todos modos, es evidente que todos ellos se encontraban bajo un riesgo mayor. 
En fin, desde mediados de la década de 1840, y durante casi 20 años, los salarios rurales privados entrerrianos no dejaron de subir. Y, a partir de 1863, y durante una década, se estancaron en un rango de entre trece y quince pesos por mes. Es decir, tuvieron una evolución inversa a lo ocurrido con la tierra (véase gráfica 1). Por tanto, es evidente que, en el primer periodo, la tierra compensó el incremento de los costos laborales, probablemente mediante el aumento en la escala de los establecimientos, o por un aprovechamiento más intenso del factor sin el pago del correspondiente canon por ese aumento de productividad. En el segundo periodo, es decir, a partir de inicios de la década de 1860, fueron los salarios la variable de ajuste. Es de apuntar que esto ocurre en un contexto rioplatense de aparente ascenso nominal de salarios; pero esos aumentos aparecen ligados a los rubros dinámicos de la economía rural: agricultura especializada, cuidado de animales finos y puros por cruza $\sqrt{30}$ Dada la tradicional inelasticidad de los mismos a la baja, quizá el estancamiento de las remuneraciones en Entre Ríos esté enmascarando un descenso de la demanda; pero ello no se verifica en las cuentas de Urquiza, ya que si bien la tendencia es levemente declinante desde 1870 (lo cual responde en realidad a la venta progresiva de algunos establecimientos), durante la década de 1860 las nóminas salariales totales alcanzan mensualmente con frecuencia el rango de 60-80 empleados, superándolo en varias ocasiones. Es, sin embargo, un factor a considerar el hecho de que, tratándose de un gran complejo empresarial, su evolución enmascare la de otras unidades más pequeñas, las cuales pueden haberse visto en dificultades mayores al respecto.

\section{COSTOS DE PRODUCGIÓN Y BENEFICIO EN EL LARGO PLAZO}

En la gráfica 2 hemos relacionado los precios de los principales productos de los establecimientos ganaderos entrerrianos de esos años (animales vacunos y ovinos), con los de los insumos productivos: salarios del personal, y equinos, necesarios para el manejo de los rebaños. Los precios están tomados de los inventarios post mortem y, como ha sido ya demostrado, los de vacunos y ovinos siguieron muy de cerca la evolución de los precios de lanas y cueros vacunos en los principales mercados externos (véase Djenderedjian, 2013). El objetivo, aquí, es evaluar hasta qué punto, durante la crisis, los costos de producción carcomieron la ganancia por unidad de producto, forzando así aún más el recurso al aumento de la escala para obtener un umbral mínimo de beneficio económico, lo cual, como puede deducirse de lo dicho antes, constituía una dificultad que se podía volver insuperable ante el creciente aumento del valor de la tierra.

Como hemos dicho, la proporción del valor de la tierra en el total del inventario se mantiene más o menos estable hasta aproximadamente inicios de la década de 1860; hasta esos años, el aumento de los salarios nominales muestra que parte creciente de los precios remunerativos de los productos de los establecimientos fue capturada por los trabajadores, sin afectar mayormente la ecuación de costos por causa del mantenimiento del recurso tierra como variable de ajuste. Es probable así que existieran aún tierras baldías, pero, de cualquier forma, como estamos efectuando todos nuestros cálculos sobre áreas ocupadas desde antiguo, se trataba en todo caso de porciones subutilizadas dentro de las mismas explotaciones. De hecho, la productividad por hectárea aumentó sustancialmente en el periodo, si juzgamos por los cambios en la carga ganadera de un establecimiento de gran envergadura perteneciente a J. J. Urquiza (véase cuadro 2).

\footnotetext{
${ }^{30} \mathrm{Al}$ menos es lo que surge de evidencia dispersa; véanse Djenderedjian, Bearzotti y Martirén (2010, II, p. 864) y Sesto (2005, pp. 139-160).
} 


\section{GRÁFICA 2. SALARIOS Y PRECIO DE EQUINOS COMO PARTE DEL PRECIO COMBINADO DE VACUNOS Y OVINOS. ENTRE RÍOS, 1853-1875}

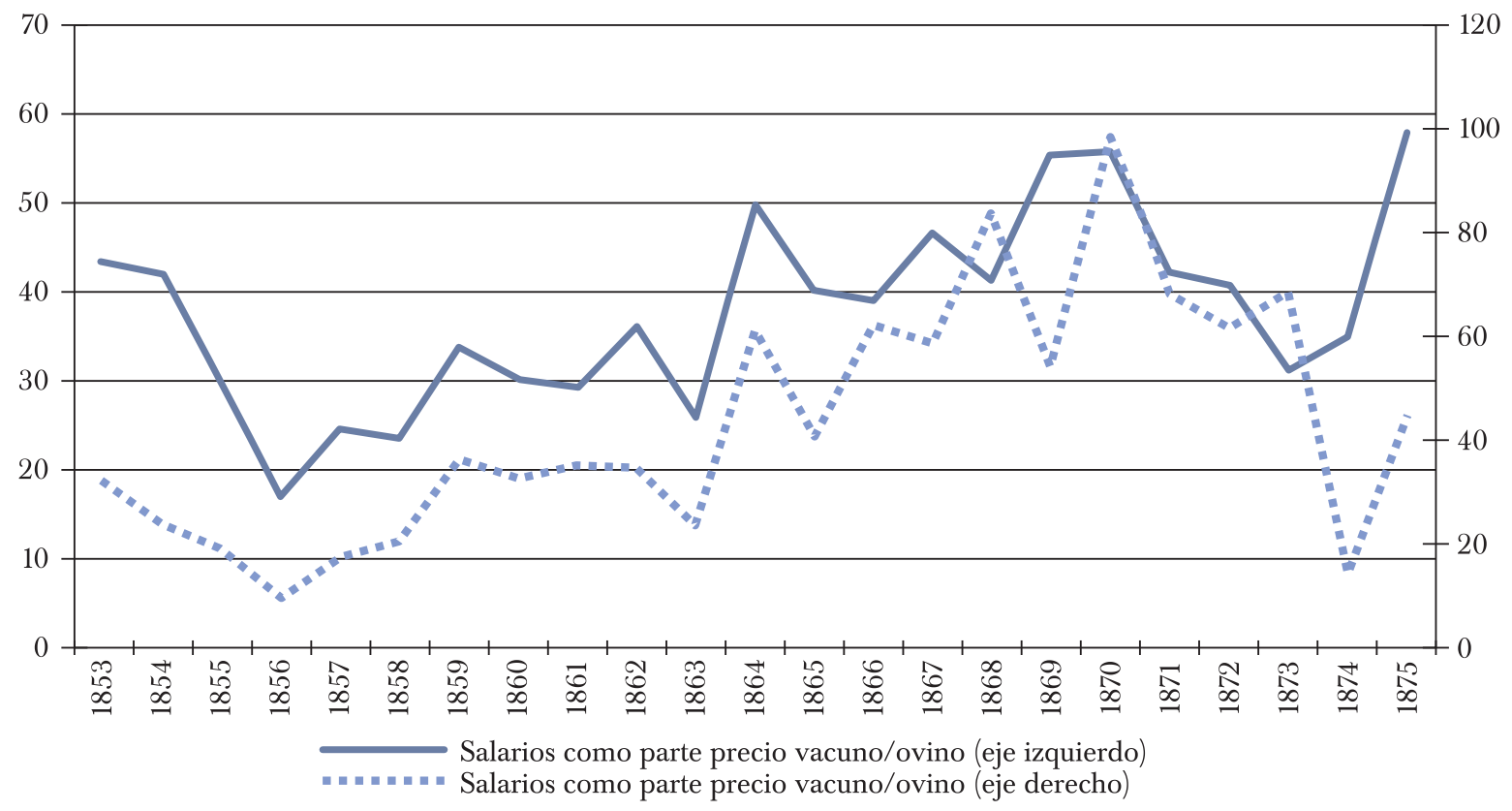

Fuente: precios de vacunos, ovinos y equinos en inventarios post mortem, en AHAER; datos de salarios en gráfica 1.

De modo que la expansión no implicó necesariamente el aumento de la oferta de tierras a través de avances sobre áreas marginales, sino que bastó con incrementar el grado de uso del factor tierra ya disponible. No hubo, por tanto, en este periodo, una "sed de acaparamiento" de tierras, conducta a la postre racional por parte de los productores ya que se justificaría en un contexto donde la extensividad era la norma; pero que en última instancia hubiera reforzado una hipotética aversión a la innovación tecnológica y una también hipotética preferencia por la obtención de renta. Nada de eso parece cierto: por el contrario, el aumento de la carga ganadera indicaría que, dentro de los límites tecnológicos de la época, se fue haciendo un uso cada vez más intensivo del recurso disponible. El problema fue que, en el momento en que más necesario se hizo incrementar la inversión de capital, la disponibilidad de este se redujo en forma acelerada, al encontrarse los productores con un escenario de rentabilidad decreciente determinado por el agotamiento de la posibilidad de intensificar el uso de la tierra disponible, en el mismo momento en que los precios de los productos que producían caían en picada, y cuando tampoco era posible reducir racionalmente la nómina laboral por la aparición de la guerra. Sumado a ello, la inexistencia de tierras de frontera sobre las que expandir el stock ganadero mantuvo la presión sobre los precios de la hectárea en las áreas ya ocupadas.

En suma, el costo de los dos factores principales de producción, la tierra y los salarios, aumenta inversamente hasta inicios de la década de 1860; pero al cambio de esa situación a partir de entonces se suman la crisis económica, la guerra y luego la contienda civil. Es evidente entonces que, a pesar de los esfuerzos anteriormente realizados para incrementar la productividad, la única manera de compensar a corto plazo los mayores costos laborales y operativos hubiera sido un 


\section{CUADRO 2. CARGA GANADERA POR HECTÁREA EN LA ESTANCIA DEL POTRERO, 1855-1872}

\begin{tabular}{lcc}
\hline \multicolumn{1}{c}{ Ganado } & 1855 & 1872 \\
\hline Vacuno & 0.07 & 0.10 \\
Ovino & 0.03 & 0.03 \\
Equino & 0.01 & 1.41 \\
Mular & 0.00 & 0.04 \\
Burros & 0.00 & 0.00 \\
Total de animales & 0.11 & 1.59 \\
Unidad ganadera (vacuno) & 0.09 & 0.37 \\
\hline
\end{tabular}

Nota: la unidad ganadera fue construida según las estimaciones del censo provincial de Buenos Aires de 1881, con base en el vacuno. Según las mismas, un vacuno equivale a: un cerdo; ocho ovejas; o 0.8 equinos, mulares o burros (véase nota 16).

Fuente: Schmit y Djenderedjian (2006).

aumento de la escala, el cual ahora habría de mostrarse difícil por el creciente peso relativo de la tierra en el costo de producción ${ }^{31}$ La inoportunidad de las acciones del gobierno en el sentido de revisar los derechos de propiedad parece entonces evidente. De todos modos, que ese aumento se debiera al menos en parte a las políticas de definición de títulos y clarificación de tenencias encaradas desde el gobierno provincial, o a la demanda de los productores, es en realidad aleatorio: la dificultad principal radicaba en que la coyuntura, súbitamente desfavorable en varios planos, y cada vez más conflictiva, no permitía encarar soluciones integrales al respecto. La misma acumulación de problemas debió potenciar la crisis: así, los soldados que regresaban del frente externo de guerra probablemente se encontraran con un panorama laboral desalentador, en el que, si bien los salarios mantenían de una u otra forma su nivel, la demanda de trabajo debía verse necesariamente debilitada por la pérdida de ventas en mercados externos, y por la destrucción que necesariamente acompañó a la conflictividad interna. Por lo demás, el aumento en el valor de la tierra y el paralelo descenso de las posibilidades de comercializar sus subproductos implicaron que el inicio de una explotación independiente, objetivo lógico de cualquier asalariado en esos años, viera sus condiciones de concreción cada vez más lejanas: no sería nada casual que esas insatisfacciones estuvieran en parte detrás de la alta conflictividad del periodo ${ }^{32}$ Es entonces recién al terminar esta, hacia

\footnotetext{
${ }^{31}$ Recordemos que durante la segunda mitad de la década de 1860 la presión de los hacendados por acceder a más tierra se vuelve viral; véase nota 25 . Esta presión puede estar relacionada también con la creciente carga ganadera de los campos bonaerenses por efecto de la rápida expansión ovina y la retracción de la frontera, en medio del descenso de la presión militar allí por efecto de la partida de buena parte de la fuerza al combate en la Guerra del Paraguay. En todo caso, tampoco las provincias vecinas ofrecían una alternativa para descargar los sobrepoblados campos entrerrianos.

${ }^{32}$ De hecho, las proclamas y documentos que nos han quedado de los revolucionarios aluden en forma directa a esas cuestiones, al enfatizar el peso de los impuestos, los arrendamientos al erario público y la presencia de inmigrantes, que competían con los criollos por los puestos de trabajo. Fondo Ricardo López Jordán, caja 4, f. 628, R. López Jordán a Pedro Seguí, Calá (27 de abril de 1870); caja 7, f. 108, Archivo de la Academia Nacional de la Historia. El Obrero Nacional (29 de agosto de 1870), editado en el campamento en marcha de los revolucionarios, afirmaba que el objeto de la inmigración era "suplir la popularidad con fuerza cosmopolita importada so pretexto de la industria". Véanse insistentes referencias acerca del peso de los impuestos que recaían sobre la población criolla en Fondo Ricardo López Jordán, caja 7, f. 84. Archivo de la Academia Nacional de la Historia
} 
1876, que los salarios vuelven a adquirir una tendencia ascendente. Pero el análisis en profundidad de ese periodo queda fuera de los límites de este trabajo. En todo caso, el alto valor relativo de la tierra en Entre Ríos continuaría pesando en el cálculo de costos 33

\section{Conclusiones}

Los productores rurales entrerrianos parecen haber actuado con racionalidad al aprovechar un ciclo de altos precios de los productos que exportaban, supliendo con un factor barato (la tierra) el aumento de costos laborales. Pero el cambio de coyuntura de inicios de la década de 1860 trajo aparejadas modificaciones sustanciales en la relación entre ambos factores, y a la vez las rigideces generadas por esa estructura agraria y productiva en los años de bonanza limitó las posibilidades de respuesta. A ello se sumó una difícil coyuntura marcada por la caída de los precios de los productos de exportación y la crisis económica consiguiente; la guerra externa, y la contienda civil. La última, en parte, quizá pueda ser atribuida a los problemas generados en la etapa previa, en tanto la variable de ajuste pasó a ser el factor trabajo, y los salarios nominales se estancaron. La extensividad, que de todas formas se fue reduciendo a lo largo del periodo, se convirtió en una trampa en la medida en que, con la llegada de la crisis, sus costos se hicieron difíciles de financiar, reduciéndose así las oportunidades y las posibilidades de progreso. Pero la extensividad de la producción ganadera entrerriana no puede atribuirse a una actitud retardataria o poco propensa a la toma de riesgos por parte de los actores de la misma: por lo que hemos mostrado, respondía a multitud de factores, y su salida no pudo ser encarada en forma integral ni sencilla a partir de la coyuntura. Las alternativas, por otro lado, como ocurría con la agricultura triguera de exportación, incluían actividades para las cuales era preciso encarar una sustantiva inversión de capital en maquinarias, o recostarse en agregados de mano de obra, esta última ya demasiado cara, y de costos crecientes. No parece por tanto que la oportunidad de encarar ese cambio fuera algo sencillo. El problema real, si se quiere, es que la creciente rigidez de los costos impidió el oportuno giro hacia actividades con mejores perspectivas de mercado; giro que hubiera significado una apuesta demasiado fuerte en cualquier momento, pero que, en una coyuntura crítica, se convirtió en un lastre demasiado pesado de remontar.

\section{LISTA DE REFERENCIAS}

Agote, P. (1881). Informe del presidente del Crédito Público Nacional. Buenos Aires: Imprenta y Encuadernación de Guillermo Kraft.

Álvarez, J. (1929). Temas de historia económica argentina. Buenos Aires: El Ateneo.

Argentina. Departamento Nacional de Agricultura (1888). Progresos rurales en Entre Ríos. La calera de Nancay. Boletín del Departamento Nacional de Agricultura, 12(3).

Argentina. Dirección de los Ferro-Carriles Nacionales (1896). Estadística de los ferro-carriles en explotación. Buenos Aires: Compañía Sud-americana de billetes de banco.

\footnotetext{
${ }^{33}$ A partir de 1888, el precio promedio de la hectárea de tierra rural de Entre Ríos era de más del triple de lo pagado en la vecina provincia de Santa Fe, y sólo era superado por los valiosos suelos de Buenos Aires, agronómicamente de mucha mayor calidad. Precios promedio de 20 pesos moneda nacional transcritos en Francisco Latzina (1889, p. 80); pero para el año anterior, valiéndose de fuentes similares, Cayetano Ripoll (1888-1889, II, pp. 330-331) informaba un valor promedio aún mayor, de 24 pesos moneda nacional.
} 
Argentina. Provincia de Entre Ríos (1872). Memoria administrativa de la jefatura política del Departamento del Paraná, año 1871. Buenos Aires: Imprenta del Porvenir.

Argentina. Provincia de Entre Ríos (1875). Recopilación de leyes, decretos y acuerdos de la Provincia de Entre-Rios, 1821. Uruguay: s. e.

Bulmer-Thomas, V. (ed.). (2010). La historia económica de América Latina desde la independencia. México: Fondo de Cultura Económica.

Djenderedjian, J. (2008). Expansión agrícola y colonización en Entre Ríos, 1850-1890. Desarrollo Económico, 47(188), 577-606.

Djenderedjian, J. (2013). Tormenta perfecta. La rebelión jordanista en Entre Ríos y los efectos del ciclo económico 1864-1873. En D. Santilli, J. Gelman, y R. Fradkin (eds.), Rebeldes con causa: conflicto y movilización popular en la Argentina del siglo XIX (pp. 169-196). Buenos Aires: Prometeo Libros.

Djenderedjian, J. y Schmit, R. (2011). La distribución de la riqueza en Entre Ríos, 1840-1880: cambios en la inversión rural en un contexto difícil. En J. Gelman (ed.), El mapa de la desigualdad en la Argentina del siglo XIX (pp. 139-170). Buenos Aires: Prohistoria Ediciones.

Djenderedjian, J., Bearzotti, S. y Martirén, J. L. (2010). Historia del capitalismo agrario pampeano: expansión agrícola y colonización en la segunda mitad del siglo XIX (vol. 2). Buenos Aires: Teseo/Universidad de Belgrano.

Fuente, D. G. de la (1872). Primer censo de la República Argentina verificado en los días 15, 16 y 17 de septiembre de 1869. Buenos Aires: Imprenta del Porvenir.

Fuente, D. G. de la., y Rocha, D. (1883). Censo general de la provincia de Buenos Aires: demográfico, agrícola, industrial, comercial: verificado el 9 de octubre de 1881. Buenos Aires: El Diario.

Fuente, D. G. de la, Carrasco, G. y Martínez, A. (1898). Segundo censo de la República Argentina: mayo 10 de 1895: decretado en la administración del Dr. Sáenz Peña, verificado en la del Dr. Uriburu. Buenos Aires: Taller tipográfico de la Penitenciaría nacional.

Garavaglia, J. C. (1999). Un siglo de estancias en la campaña de Buenos Aires: 1751 a 1853. The Hispanic American Historical Review, 79(4), 703-734.

Gelman, J. (2011). Historia contemporánea de argentina. t. 2. La construcción nacional: 1830-1880. Madrid: Instituto de Cultura de la Fundación MAPFRE.

Gelman, J. y Santilli, D. (2013). Movilidad social y desigualdad en el Buenos Aires del siglo xix: el acceso a la propiedad de la tierra entre el rosismo y el orden liberal. Hispanic American Historical Review, 93(4), 659-684. DOI: 10.1215/00182168-2351665

Gjerstad, S. D. y Smith, V. L. (2014). Rethinking Housing Bubbles The Role of Household and Bank Balance Sheets in Modeling Economic Cycles. Nueva York: Cambridge University Press.

Jurado, J. M. (1875). La estancia en Buenos Aires. Anales de la Sociedad Rural Argentina, 9(2), 3338.

Korol, J. C. y Tandeter, E. (1999). Historia económica de América Latina: problemas y procesos. México: Colegio de México/Fideicomiso Historia de las Américas/Fondo de Cultura Económica.

Latzina, F. (1889). L'agriculture et l'élevage dans la République Argentine: d'après le recensement de la première quinzaine d'octobre de 1888 fait sous les auspices de la commission chargée des travaux de la section argentine à l'Exposition de Paris. París: Mouillot.

Macchi, M. E. (1971). Urquiza, el saladerista. Buenos Aires: Macchi.

Míguez, E. J. (1985). Las tierras de los ingleses en la Argentina, 1870-1904. Buenos Aires: Editorial de Belgrano. 
Míguez, E. J. (2008). Historia económica de la Argentina: de la conquista a la crisis de 1930. Buenos Aires: Sudamericana.

Napp, R. (1876). La república argentina. Buenos Aires: Impreso por la Sociedad Anónima.

Officer, L. H. y Williamson, S. H. (2018). The Price of Gold, 1257-Present. Recuperado de https://www.measuringworth.com/datasets/gold/

Reula, F. (1969). Historia de Entre Ríos: política, étnica, económica, social, cultural y moral (vol. 2). Santa Fe: Castellví.

Ripoll, C. R. (1888). La provincia de Entre-Ríos bajo sus diversos aspectos (tt. 1-2). Paraná: Tipografía La Opinión.

Ruiz, M. (1896). La Provincia de Entre-Ríos: sus leyes sobre tierras. Paraná: Tipografía y Encuadernación Guttemberg de Miró y Pizzola. Recuperado de https://minerva.usc.es/xmlui/handle/103 $47 / 14530$

Sabato, J. (1991). Notas sobre la formación de la clase dominante argentina. Buenos Aires: Biblos.

Schmit, R. (2004). Ruina y resurrección en tiempos de guerra: sociedad, economía y poder en el oriente entrerriano posrevolucionario, 1810-1852. Buenos Aires: Prometeo Libros.

Schmit, R. D., y Djenderedjian, J. C. (2006). La empresa rural en el largo plazo: Cambios en la explotación de una gran estancia rioplatense entre el orden colonial y el nacimiento del capitalismo, 1780-1870. Boletín del Instituto de Historia Argentina y Americana Doctor Emilio Ravignani, 29, 7-49.

Sesto, C. (2005). La vanguardia ganadera bonaerense, (1856-1900). Buenos Aires: Siglo Veintiuno.

Valencia, M. (2005). Tierras públicas, tierras privadas: Buenos Aires 1852-1876. Buenos Aires: Universidad de La Plata.

Archivos

Archivo del Instituto del Profesorado Osvaldo Magnasco, Gualeguaychú, Argentina. AGN Archivo General de la Nación, Buenos Aires, Argentina.

ahaer Archivo Histórico de la Provincia de Entre Ríos, Entre Ríos, Argentina.

APSJ Archivo del Palacio San José, Concepción del Uruguay, Uruguay. 